Special issue of the 3rd International Conference on Computational and Experimental Science and Engineering (ICCESEN 2016)

\title{
Effects of Thymol and Carvacrol on Acetylcholinesterase from Drosophila melanogaster
}

\begin{abstract}
H. ASKIN ${ }^{a}$, M. YILDIZ ${ }^{a}$ AND A. AYAR ${ }^{b, *}$
${ }^{a}$ Department of Molecular Biology and Genetics, Faculty of Science, Ataturk University, Erzurum, Turkey ${ }^{b}$ Sabuncuoğlu Şerefeddin Health Services Vocational School, Amasya University, Amasya, Turkey

In this study, inhibitor effects of thymol and carvacrol were investigated in vivo and in vitro on acetylcholinesterase enzyme of Drosophila melanogaster. $\mathrm{IC}_{50}$ values, Ki constants and inhibition types were determined for the substances displaying inhibitory effect. In vivo studies, were performed on larvaes by considering $\mathrm{IC}_{50}$ values. The surviving and mortality rates were determined for the solution applied to larvaes. $\mathrm{IC}_{50}$ values of thymol and carvacrol were found to be $25 \mathrm{mM}$ and $0.175 \mathrm{mM}$, respectively. By using Lineweaver-Burk graphs, it was found that both compounds show non-competitive type of inhibition. According to results, it was concluded that carvacrol is a more effective inhibitor than thymol. We believe that these findings will contribute to the development of more potent, specific and effective inhibitors against AChE enzyme, design of new drugs for treating Alzheimer's disease and studies in pharmacological applications.
\end{abstract}

DOI: 10.12693/APhysPolA.132.720

PACS/topics: $42.62 . \mathrm{Be}$

\section{Introduction}

Acetylcholinesterase (AChE) hydrolyzes the neurotransmitter acetylcholine, performing synaptic transmission at the cholinergic brain synapses and has been an important target for mechanism-based inhibitors, due to its central role in the neurotransmission system [1]. Usage of $\mathrm{AChE}$ inhibitors is one of the therapeutic strategies improving the Alzheimer disease treatment. A potential source of AChE inhibitors can be provided by the compounds of plants [2]. Thymol and carvacrolas are phenolic monoterpenoids and are major constituents of essential oils of Lamiaceae and Verbenaceae families. These compounds have displayed antiinflammatory, antiangiogenic, antigenotoxic, antimicrobial, antimutagenic, antioxidant, antiparasitic, antiprotozoal, insecticidal, and carcinogenesis-reducing effect [3].

Drosophila melanogaster is used as a genetic model for several human diseases, including the neurodegenerative disorders such as Parkinson's, Huntington's, spinocerebellar ataxia, Alzheimer disease, oxidative stress, immunity and diabetes $[4,5]$.

\section{Methods}

D. melanogaster AChE (DmAChE) was extracted from Drosophila heads as follows. Initially, twenty frozen heads were pressed in mortar containing liquid nitrogen. Then they were homogenized in $1 \mathrm{~mL}$ of $0.1 \mathrm{M}$ phosphate buffer $(\mathrm{pH} 7.4)$ containing $0.5 \%(\mathrm{v} / \mathrm{v})$ triton X100 and centrifuged at $13000 \times \mathrm{g}$ for $15 \mathrm{~min}$ at $4{ }^{\circ} \mathrm{C}$ [6].

*corresponding author; e-mail: arif.ayar@amasya.edu.tr
The supernatant was used as enzyme source. AChE activity was determined by Ellman's method, insignificantly modified [7]. For AChE activity assay, $750 \mu \mathrm{l}$ of water, $100 \mu \mathrm{l}$ of $1 \mathrm{M}$ Tris-HCl buffer (containing $5 \mathrm{mM}$ EDTA, $\mathrm{pH} 8.0), 50 \mu \mathrm{l}$ of DTNB (0.5 mM in $1 \%$ sodium citrate), $50 \mu \mathrm{l}$ of the enzyme solution and $50 \mu \mathrm{l}$ of ATC $(10 \mathrm{mM})$ were added to a $1 \mathrm{ml}$ reaction cuvette. In the blank cuvette, $50 \mu \mathrm{l}$ of water were replaced by the same volume of ATC. The absorbance was measured at $412 \mathrm{~nm}$ with kinetic read.

The activity was measured at five different concentrations of ATC $(0.10,0.15,0.20,0.25$ and $0.30 \mathrm{mM})$. By plotting Lineweaver-Burk graphs, $K_{m}$ and $V_{\max }$ values were calculated [8]. $\mathrm{IC}_{50}$ values were obtained from activity (\%)-compounds concentration graph by measuring the enzyme activity at different inhibitor concentrations. In the mixture with inhibitor or without inhibitor, the enzyme activity was measured at the different concentrations of the substrate. Ki values were calculated from the Lineweaver-Burk graphs drawn using $1 / V$ and $1 /[S]$ values. A total of one hundred larvaes were transferred to the medium with the solutions, at concentrations showing inhibition effect. Dead and alive individuals, turned into the adult flies, were counted. The enzyme activity was measured at the adult flies.

SPSS (Statistical Package for the Social Sciences) 15.0 software was used for statistical analysis. Duncan's multiple comparison test was applied for statistical analysis. Level of statistical significance was considered as $p<0.05$. The experiments were repeated three times for each group.

\section{Results}

By using Lineweaver-Burk plot, $K_{m}$ and $V_{\max }$ values were determined as $0.217 \mathrm{mM}$ and $0.045 \mathrm{EU} / \mathrm{ml}$, respectively (Fig. 1). 


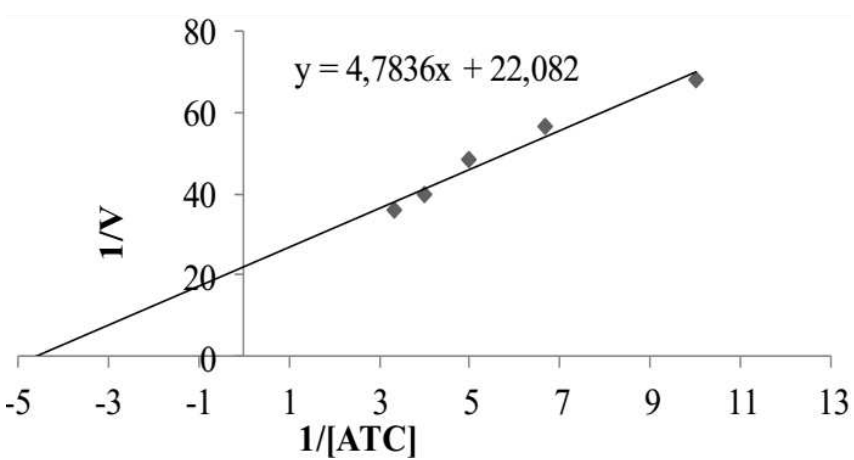

Fig. 1. Lineweaver-Burk plot drawn to calculate $K_{m}$ and $V_{\max }$ values.

$\mathrm{IC}_{50}$ values and $\mathrm{Ki}$ constants were $25 \mathrm{mM}$ and $34.9 \mathrm{mM}$ for thymol; $0.175 \mathrm{mM}$ and $0.681 \mathrm{mM}$ for carvacrol, respectively. Both compounds have shown non-competitive type of inhibition. Representative graphs are shown in Figs. 2 and 3.
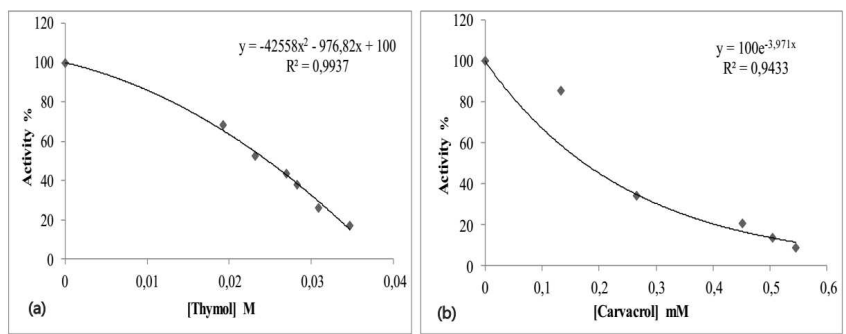

Fig. 2. Regression analysis graphs of activity \% versus concentration of compounds for DmAChE for (a) thymol and (b) carvacrol.

When these data were compared with water, there was a statistically significant difference in all treatment groups $(p<0.05)$. The results of application to larvaes are shown in Table I. The activity values of DMSO, used to dissolve thymol and carvacrol, are not shown because they were the same as for water.

TABLE I

DmAChE activity values obtained from adult individuals of larvaes subjected to thymol and carvacrol.

\begin{tabular}{c|c|c|c}
\hline $\begin{array}{c}\text { Thymol } \\
\text { concentrate } \\
{[\mathrm{mM}]}\end{array}$ & $\begin{array}{c}\text { DmAChE } \\
\text { activity } \\
\text { values }[\mathrm{EU} / \mathrm{ml}]\end{array}$ & $\begin{array}{c}\text { Carvacrol } \\
\text { concentrate } \\
{[\mathrm{mM}]}\end{array}$ & $\begin{array}{c}\text { DmAChE } \\
\text { activity } \\
\text { values }[\mathrm{EU} / \mathrm{ml}]\end{array}$ \\
\hline Control & $0.061^{a}$ & Control & $0.061^{a}$ \\
20 & $0.065^{b}$ & 0.075 & $0.060^{a}$ \\
25 & $0.063^{b}$ & 0.125 & $0.059^{a}$ \\
30 & $0.056^{c}$ & 0.175 & $0.060^{a}$ \\
35 & $0.053^{d}$ & 0.225 & $0.056^{b}$ \\
\hline
\end{tabular}

${ }^{*}$ There is no statistically significant difference between the values shown with the same letter in the same column $(p<0.05)$. The compounds were compared independently.
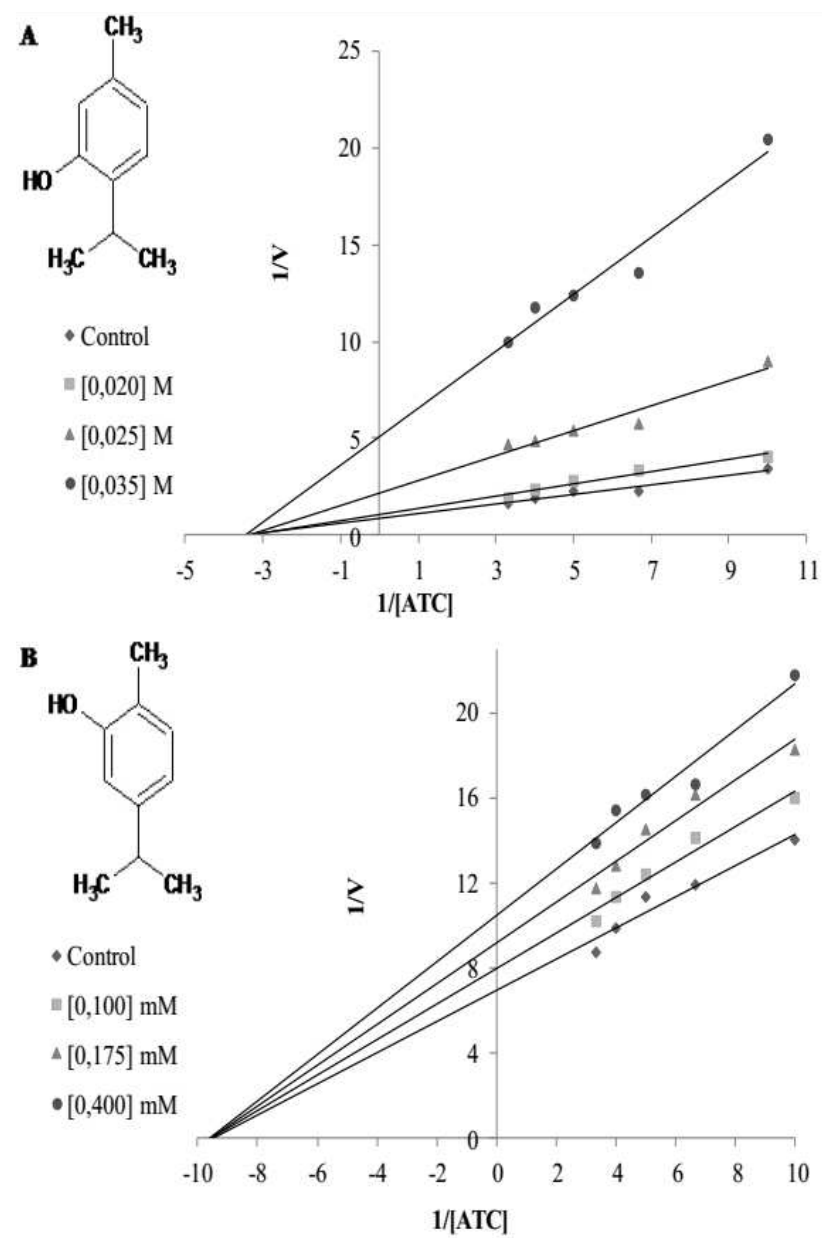

Fig. 3. Lineweaver-Burk graphs using three different concentrations of thymol (a) and carvacrol (b) for determination of Ki.

For the larvaes exposed to different concentrations of thymol and carvacrol, survival and mortality rates are displayed in Table II.

TABLE II

Mortality and survival ratio of the treated larvae.

\begin{tabular}{c|c|c|c}
\hline \hline $\begin{array}{c}\text { Application } \\
\text { groups }\end{array}$ & $\begin{array}{c}\text { Concentration } \\
{[\mathrm{mM}]}\end{array}$ & $\begin{array}{c}\text { Mortality } \\
\text { ratio [\%] }\end{array}$ & $\begin{array}{c}\text { The survival } \\
\text { ratio [\%] }\end{array}$ \\
\hline Water & - & $1^{a}$ & $99^{a}$ \\
\hline DMSO & 0.01 & $10^{b}$ & $90^{b}$ \\
\hline & 20 & $14^{c}$ & $86^{c}$ \\
Thymol & 25 & $19^{d}$ & $81^{d}$ \\
& 30 & $37^{e}$ & $63^{e}$ \\
& 35 & $35^{f}$ & $65^{e}$ \\
\hline & 0.075 & $12^{c}$ & $88^{c}$ \\
Carvacrol & 0.125 & $13^{c}$ & $89^{b c}$ \\
& 0.175 & $17^{d}$ & $83^{d}$ \\
& 0.225 & $18^{d}$ & $82^{d}$ \\
\hline
\end{tabular}

*There is no statistically significant difference between the values shown with the same letter in the same column $(p<0.05)$. Thymol and carvacrol were compared with water and DMSO independently. 
It is believed that the results and conditions of in vivo and in vitro tests were not equivalent to each other due to differences in physiological changes, defense systems and the properties of resistance in animals. Because of the different position of the hydroxyl groups in the structure of these compounds, each of them may show different effect. $\mathrm{IC}_{50}$ values of thymol and carvacrol were calculated as $25 \mathrm{mM}$ and $0.175 \mathrm{mM}$, respectively. It was shown that carvacrol has smaller $\mathrm{IC}_{50}$ values than thymol. The inhibitor having small $\mathrm{IC}_{50}$ values indicates a great interest in the enzyme and a higher inhibitory effect.

\section{Conclusions}

In this study, we report that thymol and carvacrol show significant AChE inhibitory activities. The results indicate that using thymol and carvacrol for AChE inhibition may provide development of more potent, specific and effective inhibitors against AChE enzyme and useful compounds in the design of new drugs for the treatment of Alzheimer's disease. The further investigation of native compounds in plants is ongoing.

\section{Acknowledgments}

This study was supported Scientific Research Projects of Ataturk University (project number: BAP 2012/482).

\section{References}

[1] D.M. Quinn, Chem. Rev. 87, 955 (1987).

[2] S. Dall'Acqua, Botanics: Targets Therapy 3, 19 (2013).

[3] K.H. Baser, Current Pharmaceut. Des. 14, 3106 (2008).

[4] L.T. Reiter, L. Potocki, S. Chien, M. Gribskov, E. Bier, Genome Res. 11, 1114 (2001).

[5] S. Lenz, P. Karsten, J.B. Schulz, A. Voigt, J. Neurochem. 127, 453 (2013).

[6] Y.M. Hsiao, J.Y. Lai, H.Y. Liao, H.T. Feng, J. Agricult. Food Chem. 52, 5340 (2004).

[7] G.L. Ellman, K.D. Courtney, V. Andes, R.M. Featherstone, Biochem. Pharmacol. 7, 88 (1961).

[8] H. Lineweaver, D. Burk, J. Am. Chem. Soc. 56, 658 (1934). 